\title{
COMPOSIÇÃO QUÍMICA E ATIVIDADE ALELOPÁTICA DO ÓLEO VOLÁTIL DE Hydrocotyle bonariensis LAM (ARALIACEAE)
}

\section{Cristiane B. da Silva}

Departamento de Ciências Biológicas e da Saúde, Universidade Federal do Mato Grosso do Sul, 79070-900 Campo Grande - MS, Brasil Euclésio Simionatto, Sônia C. Hess e Marize T. L. P. Peres*

Departamento de Hidráulica e Transportes, Universidade Federal de Mato Grosso do Sul, 79070-900 Campo Grande - MS, Brasil Edésio L. Simionatto e Alberto W. Júnior

Departamento de Química, Fundação Universidade Regional de Blumenau, 89010- 904 Blumenau - SC, Brasil

Nilva R. Poppi

Departamento de Química, Universidade Federal de Mato Grosso do Sul, 79070-900 Campo Grande - MS, Brasil

Odival Faccenda

Departamento de Ciências da Computação, Universidade Estadual de Mato Grosso do Sul, 79804-970 Dourados - MS, Brasil

Ana C. da Silva Cândido e Silvana de P. Q. Scalon

Departamento de Ciências Agrárias, Universidade Federal da Grande Dourados, 79804-970 Dourados - MS, Brasil

Recebido em 11/12/08; aceito em 16/5/09; publicado na web em 10/11/09

CHEMICAL COMPOSITION AND ALLELOPHATIC ACTIVITY OF ESSENTIAL OIL FROM Hydrocotyle bonariensis Lam (ARALIACEAE). The volatile oil obtained from the leaves of Hydrocotyle bonariensis Lam (Araliaceae) was analyzed by GC, ChiralGC and GC-MS. It was identified 14 compounds and the monoterpene (+)-limonene (53.6\%) and sesquiterpene $\gamma$-muurolene (10.5\%) were the main components. The allelopathic effects of the oil were evaluated against two seeds, Lactuca sativa and Allium cepa. The results show that the oil exhibited inhibition effects in the germination and seedling growth of plants species relative to the control.

Keywords: Araliaceae; (+)-limonene; allelopathic effects.

\section{INTRODUÇÃO}

Os óleos essenciais são líquidos aromáticos obtidos de materiais vegetais (flores, folhas, ramos, sementes, ervas, madeira, frutos, raízes e cascas), sendo constituídos por misturas complexas, dentre outras, de terpenoides que podem conter até 100 ou mais compostos orgânicos. Os terpenos encontrados com maior frequência nos óleos essenciais são os monoterpenos, sesquiterpenos e com menor frequência os diterpenos. Seus constituintes terpênicos podem apresentar diversas funções orgânicas, como álcoois, cetonas, éteres, ésteres e aldeídos. Os terpenos possuem, também, diversas funções nas plantas atuando como fitoalexinas, repelentes de insetos, agentes de atração polínica, agentes de defesa contra herbívoros, feromônios, hormônios vegetais, moléculas de sinalização e aleloquímicos. ${ }^{1}$

A ação alelopática pode afetar toda a fisiologia da planta, bem como a composição e a quantidade de enzimas específicas que funcionam como catalisadores durante o metabolismo, influenciando nos estágios de desenvolvimento e crescimento, e estes estágios podem estar associados a outros fatores como estresses abióticos, salinidade do solo, umidade e temperatura. ${ }^{2}$ Um grande número de plantas desenvolvem um sistema de defesa para proteção contra herbívoros e, quando atacadas, emitem substâncias voláteis, que podem ser constituídas por mono e/ou sesquiterpenos. ${ }^{3}$

A família Araliaceae distribui-se em todo o território brasileiro, com 40 gêneros e 1500 espécies. ${ }^{4} \mathrm{O}$ gênero Hydrocotyle é representado por 16 espécies, sendo a maioria dos representantes aquáticos ou de lugares úmidos. ${ }^{5}$ Hydrocotyle bonarienis LAM. é conhecida popularmente como erva-de-capitão ou acariçoba. A planta é nativa nas Américas, ocorrendo dos Estados Unidos até a Argentina e o Chile, sendo mencionada como infestante em arroz no Peru. No

*e-mail: mperes@hotmail.com
Brasil, tem vasta distribuição, especialmente na região costeira, sendo uma planta infestante com facilidade de adaptação a climas variados, espalhando-se rapidamente, podendo ocorrer desde solos secos até na areia das restingas e praias da Costa Atlântica, onde é particularmente mais frequente. ${ }^{6}$ Suas raízes são diuréticas, usadas em obstrução hepática, como aperientes, amargas e tônicas e em altas doses são eméticas e as folhas são usadas externamente, para tirar manchas da pele. A planta toda também é utilizada no combate às afecções do baço, fígado, intestino, diarréia, reumatismo e sífilis. ${ }^{7}$

O presente trabalho foi realizado com o objetivo de determinar a composição química do óleo volátil extraído das folhas de $H$. bonariensis, e avaliar o potencial de atividade alelopática, por meio de bioensaios de germinação e crescimento de Lactuca sativa (alface) e Allium cepa (cebola), em laboratório.

\section{RESULTADOS E DISCUSSÃO}

O óleo volátil das folhas de $H$. bonariensis, obtido através do processo de hidrodestilação, teve um rendimento de $0,6 \%$, sendo aqui sua composição química descrita pela primeira vez. Os componentes químicos identificados no óleo de H. bonariensis, incluindo seus respectivos índices de retenção e porcentagens, estão sumarizados na Tabela 1. Foi possível identificar 14 compostos, representando $77,1 \%$ da composição química total do óleo, o qual é constituído principalmente por monoterpenos $(58,1 \%)$ seguidos de sesquiterpenos (19\%). Os compostos majoritários presentes no óleo volátil de $H$. bonariensis foram o monoterpeno limoneno, com concentração de $53,6 \%$, seguido do sesquiterpeno $\gamma$-muuroleno com $10,5 \%$, o que corresponde a $64,1 \%$ do total. Outros componentes identificados em teores significativos foram $E$-cariofileno $(2,7 \%)$, sabineno $(1,9 \%), \alpha$-copaeno $(1,8 \%), \delta$-cadineno $(1,4 \%)$ e $\gamma$-terpineol $(0,9 \%)$. 
Tabela 1. Composição química do óleo volátil das folhas de Hydrocotyle bonariensis Lam (Araliaceae)

\begin{tabular}{llcc}
\hline Compostos $^{\mathrm{a}}$ & $\%$ & $\mathrm{RI}^{\mathrm{bc}}$ \\
\hline 01 & $\alpha$-tujeno & 0,5 & 930 \\
02 & sabineno & 1,9 & 973 \\
03 & $\beta$-pineno & 0,4 & 983 \\
04 & (+)-limoneno & 53,6 & 1030 \\
05 & linalol & 0,8 & 1102 \\
06 & $\gamma$-terpineol & 0,9 & 1198 \\
07 & $\alpha$-copaeno & 1,8 & 1377 \\
08 & $\alpha$-cubebeno & 0,5 & 1389 \\
09 & Ni ${ }^{\mathrm{d}}$ & 0,6 & 1398 \\
10 & $E$-cariofileno & 2,7 & 1421 \\
11 & $\alpha$-trans-bergamoteno & 0,7 & 1434 \\
12 & $\alpha$-humuleno & 0,6 & 1457 \\
13 & $\beta$-santaleno & 0,8 & 1461 \\
14 & Ni d,e & 8,9 & 1465 \\
15 & $\gamma$-muuroleno & 10,5 & 1482 \\
16 & Ni & 1,2 & 1489 \\
17 & $\delta$-cadineno & 1,4 & 1520 \\
& Monoterpenos id. & 58,1 & \\
& Sesquiterpenos id. & 19,0 & \\
& TOTAL & 87,9 & \\
\hline & & & \\
& & &
\end{tabular}

${ }^{\mathrm{a} C o m p o s t o s ~ l i s t a d o s ~ e m ~ o r d e m ~ d e ~ e l u i c ̧ a ̃ o ~ n a ~ c o l u n a ~ Z B-5 ; ~ b I R ~ i ́ n d i c e s ~ d e ~}$ retenção; ' Índices obtidos por temperatura programada e determinados na coluna apolar ZB-5 $\left(50-250{ }^{\circ} \mathrm{C} ; 3{ }^{\circ} \mathrm{C} / \mathrm{min}\right)$; ${ }^{\mathrm{N}} \mathrm{N}$.i.: substância não identificada por IR e pelas bibliotecas consultadas; ${ }^{e}$ Fragmentação observada $\mathrm{m} / \mathrm{z}(\%)$ : $204\left[\mathrm{M}^{+}(1 \%)\right], 189(3 \%), 161(18 \%), 137(100 \%), 121(11 \%), 105(11 \%)$, $95(33 \%), 81(16 \%), 67(18 \%)$.

Devido ao fato de ser o monoterpeno quiral limoneno o principal componente do óleo volátil de $H$. bonariensis, torna-se necessária a investigação de sua estereoquímica. O limoneno de ocorrência natural pode ser encontrado nas formas enantioméricamente puras (+) e (-), em misturas racêmicas, como também nas formas enriquecidas de seus enantiômeros. ${ }^{8,9}$ No óleo de $H$. bonariensis, o limoneno foi analisado quanto a sua composição enantiomérica, utilizando-se uma coluna capilar empacotada com a fase quiral 2,6-Me-3-Pe- $\beta$-CD, padrões racêmicos e enantiomericamente puros. Após estas análises constatou-se que no óleo volátil de $H$. bonariensis, o limoneno possui o isômero de configuração (+) na forma enantiomericamente pura, ou seja, com excesso enantiomérico de $100 \%$ do (+)-limoneno.

Os monoterpenoides estão presentes na composição da maioria dos óleos essenciais de plantas e são, dentro desse grupo, os que têm sido identificados com maior potencialidade alelopática, influenciando na germinação de sementes e na inibição do crescimento da raiz. ${ }^{10}$

Em relação ao processo germinativo, foi verificado que todas as concentrações do óleo volátil de $H$. bonariensis reduziram significativamente a porcentagem de germinação em Lactuca sativa (alface) e Allium cepa (cebola), sendo as reduções de 54\% em Lactuca sativa e $34 \%$ em Allium cepa, em relação ao controle, para a maior concentração ensaiada (1\%) (Tabela 2).

Os dados referentes à correlação de Pearson indicaram que existe uma forte correlação negativa para todos os parâmetros avaliados, e observa-se que, à medida que ocorre um aumento na concentração de óleo, ocorre uma diminuição nas variáveis observadas, sendo estas a germinação, o crescimento da raiz e hipocótilo/coleóptilo e massa seca (Tabela 3). Entre as espécies e variáveis avaliadas, foi verificado que o óleo volátil causou maior efeito sobre a germinação de cebola $(-0,905)$ e no peso seco de alface $(-0,865)$, evidenciando que existe uma relação dose-dependente para todos os parâmetros avaliados sendo, portanto, maiores para a germinação de Allium cepa e o peso seco de Lactuca sativa.

Tabela 3. Coeficiente de correlação de Pearson das variáveis nas concentrações do óleo de $H$. bonariensis na porcentagem de germinação de Lactuca sativa (alface) e Allium cepa (cebola)

\begin{tabular}{lcc}
\hline Variáveis & Lactuca sativa & Allium cepa \\
\hline Germinação & $-0,758^{* *}$ & $-0,905^{* *}$ \\
Crescimento da raiz & $-0,825^{* *}$ & $-0,848^{* *}$ \\
Crescimento do & $-0,863^{* *}$ & $-0,786^{* *}$ \\
hipocótilo/coleóptil & $-0,865^{* *}$ & $-0,581^{* *}$ \\
Massa seca &
\end{tabular}

** Correlação significativa ao nível 0,01 (bilateral).

No crescimento radicial das plântulas avaliadas foi verificado uma inibição significativa no crescimento da raiz de Lactuca sativa e Allium cepa em todas as concentrações ensaiadas, sendo que na menor concentração em Allium cepa não foi constatada diferença significativa. Na maior concentração (1,0\%), foi observada inibição de $40 \%$ na raiz primária de Lactuca sativa e $56 \%$ em Allium cepa, em relação ao controle. No crescimento do hipocótilo em Lactuca sativa, as menores concentrações $(0,12$ e $0,25 \%$ ) estimularam o alongamento do hipocótilo entre 4 e $7 \%$, respectivamente, e as maiores concentrações $(1,0 \%)$ inibiram o crescimento do hipocótilo de Lactuca sativa (20\%). Em Allium cepa, foi verificada inibição no crescimento do coleóptilo, em todas as concentrações ensaiadas, e observa-se uma relação dosedependente, sendo a inibição de $45 \%$ na concentração de $1,0 \%$, em relação ao controle (Figura 1).

Em relação à massa seca (Figura 1), houve redução no acúmulo de massa das plântulas de Lactuca sativa e Allium cepa, em todas as concentrações ensaiadas, em $\pm 35 \%$ em Lactuca sativa e $\pm 50 \%$ em Allium cepa, em relação ao controle, na concentração de $1,0 \%$. Os resultados obtidos sugerem que o óleo volátil das

Tabela 2. Efeito das concentrações do óleo essencial das folhas de H. bonariensis na porcentagem de germinação de Lactuca sativa (alface) e Allium cepa (cebola)

\begin{tabular}{lllllll}
\hline \multicolumn{7}{l}{ Porcentagem de germinação* } \\
\hline & Controle & $0,05 \%$ & $0,12 \%$ & $0,25 \%$ & $0,5 \%$ & $1 \%$ \\
Lactuca sativa & $96,5 \pm 2,5 \mathrm{a}$ & $70,0 \pm 1,6 \mathrm{~b}$ & $62,0 \pm 1,6 \mathrm{~b}$ & $54,0 \pm 2,3 \mathrm{~b}$ & $53,0 \pm 2,0 \mathrm{~b}$ & $43,5 \pm 2,5 \mathrm{~b}$ \\
Allium cepa & $96,5 \pm 2,5 \mathrm{a}$ & $88,0 \pm 2,3 \mathrm{~b}$ & $79,0 \pm 2,5 \mathrm{~b}$ & $76,5 \pm 1,9 \mathrm{~b}$ & $70,0 \pm 1,6 \mathrm{~b}$ & $65,5 \pm 1,9 \mathrm{~b}$ \\
\hline
\end{tabular}

${ }^{1}$ Médias seguidas de mesma letra do controle não diferem entre si pelo teste de Dunnet a 5\% de probabilidade. ${ }^{*}$ Média \pm Desvio padrão. 

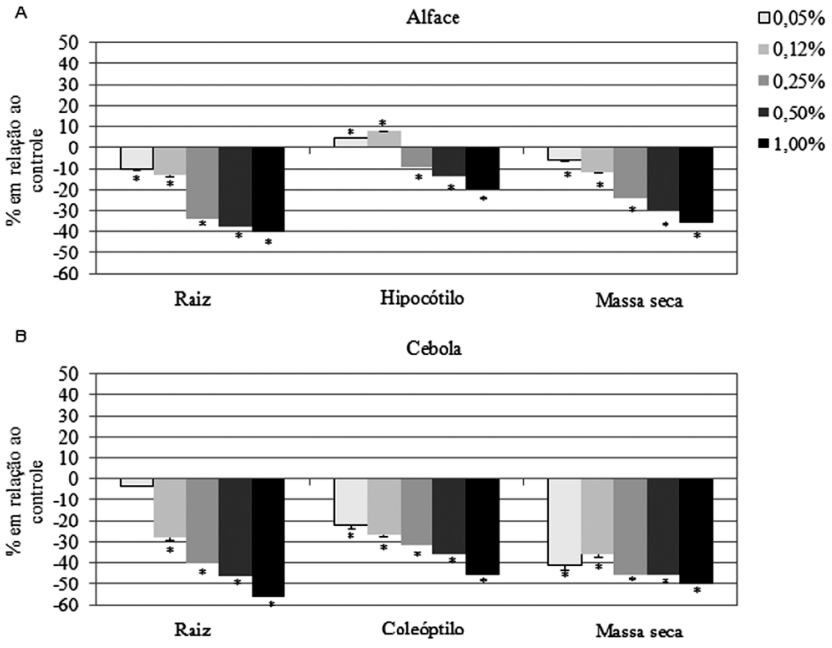

Figura 1. Efeito das concentrações do óleo essencial de H. bonariensis no crescimento da raiz e hipocótilo/coleóptilo e acúmulo de massa seca de alface (A) e cebola (B). Dados expressos em percentual em relação ao controle. *A média do tratamento difere significativamente $(p<0,05)$ em comparação com a média do controle, pelo teste de Dunnet

folhas de $H$. bonariensis contém substâncias químicas, que agem em processos fisiológicos reduzindo o acúmulo de massa seca das plântulas ensaiadas. Durante a condução dos experimentos, foi observado que nos casos de estímulo, no crescimento das raízes, estas se apresentaram mais finas e levemente oxidadas, enquanto que na inibição, foi verificado o engrossamento das raízes, além da ausência de pelos absorventes.

A atividade alelopática raramente é resultado de uma única substância, sendo mais comum um conjunto de substâncias apresentando tal atividade. O entendimento das inter-relações complica-se pelo fato de um mesmo composto influenciar várias funções biológicas e a mesma função poder ser influenciada por mais de um composto. Por exemplo, monoterpenos como $\alpha$-pineno e limoneno inibem o ciclo de nitrogênio; e os ácidos ferúlico e $\gamma$-cumárico influenciam a germinação de Brassica napus L. pela redução da mobilização lipídica. ${ }^{11}$

De acordo com os resultados, pode-se supor que os compostos químicos presentes no óleo volátil de $H$. bonariensis afetam algum processo fisiológico durante a germinação de espécies. Em Allium cepa foi verificado que o efeito alelopático foi mais evidente no crescimento radicial das plântulas do que na porcentagem final de sementes germinadas, fato também observado por Periotto et al., em estudos com extratos de Andira humilis Mart. ex Benth sobre Lactuca sativa L. e Raphanus sativus L.. ${ }^{12}$ Comparando-se o crescimento da raiz e da parte aérea (hipocótilo/coleóptilo), observa-se que os efeitos alelopáticos foram mais evidentes no crescimento da raiz do que no da parte aérea. Este fenômeno pode ter ocorrido devido à absorção e, consequentemente, a concentração de fitotoxinas nos tecidos radiculares ser favorecida pelo contato físico da raiz com o papel filtro. Desta forma, a bioatividade dos compostos voláteis está condicionada à capacidade de absorção, translocação e mecanismo de ação dos seus compostos potencialmente alelopáticos. ${ }^{13}$

\section{CONCLUSÕES}

A constituição química do óleo volátil das folhas de $H$. bonariensis revelou ser rica em monoterpenos $(58,1 \%)$, sendo que o $(+)$ limoneno, por ser o constituinte majoritário $(53,6 \%)$ aqui identificado, pode estar atuando de modo isolado ou sinergístico, com os outros monoterpenos e sesquiterpenos do óleo, provocando alterações na germinação e no crescimento das espécies alvo em estudo. Constata-se desta forma que o óleo volátil de H. bonariensis apresenta potencialidades alelopáticas, as quais provavelmente têm relação com o aspecto dominante de populações desta espécie.

\section{PARTE EXPERIMENTAL}

\section{Material vegetal}

As folhas de $H$. bonariensis foram coletadas no Horto de Plantas Medicinais da UFGD, Dourados- MS. A identificação da planta foi determinada pelo Prof. Dr. Alan Sciamarelli, do Departamento de Biologia da UFGD. Uma exsicata da planta encontra-se depositada no Herbário DDMS da Universidade Federal da Grande Dourados sob $\mathrm{n}^{\circ}$ de registro 2190 .

\section{Extração do óleo volátil}

As folhas frescas de H. Bonariensis foram submetidas a várias extrações por hidrodestilação durante $4 \mathrm{~h}$ em aparelho do tipo Clevenger modificado, seguido pela extração exaustiva do destilado com hexano. Após a remoção do solvente, o rendimento do óleo bruto foi calculado em relação ao material fresco.

\section{Análise química}

As análises em cromatografia gasosa foram realizadas em um aparelho Varian CP-3800, equipado com coluna capilar de sílica fundida ZB-5 (5\%-fenil-95\%-dimetilpolissiloxano) [30 m x 0,25 mm, espessura do filme 0,2 $(\mu \mathrm{m})$ ], obtida da Phenomenex (Torrance, CA, USA). As condições de injeção foram: hidrogênio como gás carreador ( $1 \mathrm{~mL} / \mathrm{min})$; injetor split/splitless à $220^{\circ} \mathrm{C}$; detector FID (detector de ionização em chama) à $280^{\circ} \mathrm{C}$; temperatura do forno foi de 50 à $250{ }^{\circ} \mathrm{C}$ com rampa de aquecimento de $4{ }^{\circ} \mathrm{C} / \mathrm{min}$. As análises em CG-EM foram realizadas em um sistema Varian GC-MS-MS, equipado com um cromatógrafo gasoso Varian - 3900, equipado com coluna capilar ZB-5, um injetor 1077 , um injetor automático CP-8410, acoplado a um espectrômetro de massas Varian Saturn 2100, operando com impacto de elétrons de $70 \mathrm{eV}$, nas mesmas condições da análise em CG/FID. A identificação dos componentes do óleo foi baseada em comparações dos tempos de retenções, pela determinação e comparação dos índices retenção de Kovats, e espectros de massas da biblioteca NBS/ NIST com os índices descritos por Adams. ${ }^{14}$ Uma série homologa de n-alcanos $\left(\mathrm{C}_{8}-\mathrm{C}_{32}\right)$ foi utilizada para o cálculo dos índices de retenção de Kovats. A análise quiral do limoneno foi realizada em um aparelho Varian CP-3800, com coluna empacotada com a fase quiral 2,6-Me-3-Pe- $\beta$ - $\mathrm{CD}$, com o programa de temperatura de $40-180{ }^{\circ} \mathrm{C}$ e rampa de $3{ }^{\circ} \mathrm{C} / \mathrm{min}$. A determinação da configuração absoluta do limoneno foi baseada em injeções e coinjeções com a mistura racêmica e padrões enantiomericamente puros de (+) e (-)-limoneno.

\section{Bioensaios em laboratório}

Os bioensaios de germinação e crescimento foram realizados no Laboratório de Pesticidas Naturais - UFMS. Para o preparo das soluções 0,250 mg do óleo essencial foi emulsionado com Tween 80 , na proporção 1:1 (v/v) e dissolvido em água destilada, obtendo-se a solução estoque na concentração de $1 \%$. As demais concentrações $(0,5,0,25,0,12$ e $0,05 \%)$ foram preparadas por diluição. Como controle, foi utilizada uma solução de Tween 80 a 1,0\% v/v..$^{15,16}$ 
Para os bioensaios de germinação, as placas de Petri $(9,0 \mathrm{~cm}$ de diâmetro) contendo papel filtro Whatman $\mathrm{n}^{\circ} 1$ receberam 5,0 $\mathrm{mL}$ de água destilada. Em seguida, foram semeados aleatoriamente sobre cada disco de papel filtro 50 diásporos da espécie alvo (alface e cebola) distribuídas aleatoriamente, com quatro repetições para cada solução. ${ }^{17}$ Após a semeadura, 3,0 mL da solução de cada concentração dos óleos voláteis foi distribuído em dois papéis filtro, colados na tampa da placa, evitando o contato direto com as sementes. ${ }^{15}$ Como controle procedimento similar foi utilizado, porém, com ausência das soluções contendo os óleos voláteis.

As placas de Petri contendo os diásporos foram fechadas e envolvidas com filme plástico e levadas a uma câmara de germinação, com condições de luz $(160 \mathrm{~W})$, umidade relativa $( \pm 80 \%)$ e temperatura constantes, adequadas à espécie alvo (alface, $25^{\circ} \mathrm{C}$ com luz interna constante e cebola, $15{ }^{\circ} \mathrm{C}$ e fotoperíodo de $12 \mathrm{~h}$ ). ${ }^{18}$ Após quatro dias de incubação para alface e cinco dias para cebola foi determinada a porcentagem de germinação, tendo como critério a protrusão radicular com no mínimo 2,0 mm de comprimento. ${ }^{19}$

Para os bioensaios de crescimento, as sementes foram inicialmente germinadas em placas de Petri contendo papel filtro umedecidas com 5,0 mL de água destilada. Após a germinação, tendo como critério a protrusão radicular de no mínimo $2,0 \mathrm{~mm}$ de comprimento, foram selecionadas 80 plântulas (quatro repetições de 20), para cada tratamento, sendo então transferidas para as placas de Petri contendo as soluções tratamento, utilizando-se procedimento similar ao descrito nos bioensaios de germinação. ${ }^{19}$ A leitura foi feita após quatro dias da incubação, com a medida do alongamento da raiz primária e do hipocótilo/coleóptilo (10 plântulas por placa) utilizando-se papel milimetrado. Posteriormente essas plântulas foram levadas a uma estufa a $60^{\circ} \mathrm{C}$ até peso constante, para a obtenção da massa seca.

Os dados foram submetidos à análise de variância e quando os efeitos dos tratamentos foram significativos, $(\mathrm{p}<0,05)$, em relação à testemunha, as médias foram comparadas pelo teste de Dunnet. Quando uma das pressuposições exigidas pelo modelo paramétrico não foi atendida utilizaram-se os testes estatísticos não paramétricos, Kruskal-Wallis como alternativa para a análise de variância e o Mann-Whitney como alternativa para o teste de Dunnet. Todos os resultados foram analisados considerando o nível de significância $\alpha=5 \%$.

A germinabilidade $(\% \mathrm{G})$ foi calculada segundo a metodologia descrita por Labouriau. ${ }^{18} \mathrm{O}$ coeficiente de Correlação de Pearson bilateral foi utilizado para verificar o grau de associação das concentrações do óleo, com as variáveis investigadas, sendo estas a germinação, o crescimento da raiz primária, hipocótilo/ coleóptilo e massa seca.

\section{AGRADECIMENTOS}

Ao Prof. Dr. A. Sciamarelli, pela identificação botânica. A PROPP/UFMS e FUNDECT/MS, pelo auxílio financeiro. Ao CNPq pelas concessões de bolsas de estudo.

\section{REFERÊNCIAS}

1. Burt, S.; Int. J. Food Microbiol. 2004, 94, 223; Robbers, J. E.; Speedie, M. K.; Tyler, V. E.; Phamacognosy and Pharmacobiotechnology, Willians \& Wilkins: Baltimore, 1997; Castro, H. G.; Oliveira, L. O.; Barbosa, L. C. A.; Ferreira, F. A.; Silva, D. J. H.; Mosquim, P. R.; Nascimento, E. A.; Quim. Nova 2004, 27, 55; Harborne, J. B.; Ecological biochemistry, $4^{\text {th }}$ ed., London Academic: London, 1993.

2. Ferreira, A.G.; Áquila, M. E. A.; Rev. Bras. Fis. Veg. 2000, 12, 175.

3. Pinto, C. A.; Silva, D. H. S.; Bolzani, V. S.; Lopes, N. P.; Epifanio, R. A.; Quim. Nova 2002, 25, 45.

4. Henwood, M. J.; Hart, J. M.; Edinb. J. Bot. 2001, 58, 269.

5. Fiaschi, P.; Pirani, J. R.; Bol. Bot. Univ. S. Paulo 2005, 23, 267.

6. Kissmann, K. G.; Plantas infestantes e nocivas, $2^{\text {nd }}$ ed., Tomo III., BASF: São Paulo, 1997.

7. Lorenzi, H.; Plantas daninhas do Brasil: terrestres e aquáticas, parasitas e tóxicas, $3^{\mathrm{a}}$ ed., Instituto Plantarum: Nova Odessa, 2000.

8. Simionatto, E.; Porto, C.; Dalcol, I. I.; da Silva, U. F.; Morel, A. F.; Planta Med. 2005, 71, 759.

9. Simionatto, E.; Porto, C.; da Silva, U. F.; Squizani, A. M.; Dalcol, I. I.; Morel, A. F.; J. Braz. Chem. Soc. 2005, 16, 1458.

10. Vickery, M. L.; Vickery, B.; Secondary Plant Metabolism, $2^{\text {nd }}$ ed., The Macmillan Press Ltda: Hong Kong, 1981.

11. Malheiros, A.; Peres, M. T. L. P. Em Alelopatia: interações químicas entre espécies, Yunes, R. A.; Calixto, J. B., eds.; Moderna: Chapecó, 2001.

12. Periotto, F.; Perez, S. C. J. G. A.; Lima, M. I. S.; Acta Bot. Bras. 2004, 18,3 .

13. Correia, N. M.; Centurion, M. A. P. C.; Alves, P. L. C. A.; Cienc. Rural 2005, 35, 498.

14. Adams, R. P.; Identification of essential oil components by gas chromatography/mass spectroscopy, Illinois Allured - USA: Publishing, 1995.

15. Alves, M. C. S.; Medeiros-Filho, S.; Inneco, R.; Torres, S. B.; Pesq. Agrop. Bras. 2004, 11, 1083.

16. Peres, M. T. L. P.; Simionatto, E.; Hess, S. C.; Bonani, V. F. L.; Cândido, A. C. S.; Castelli, C.; Poppi, N. R.; Honda, N. K.; Cardoso, C. A. L.; Faccenda, O.; Quim. Nova 2009, 32, 897.

17. Brasil, Ministério da Agricultura e Reforma Agrária; Regras para a Análise de Sementes, SNDA/DNDU/CLU: Brasília. 1992.

18. Laboriau, L. G.; A Germinação das Sementes, Secretaria geral da organização dos Estados Americanos: Washington D.C, 1983.

19. Ferreira, A. G.; Áquila, M. E. A.; Rev. Bras. Fisiol. Veg. 2000, 12, 175. 